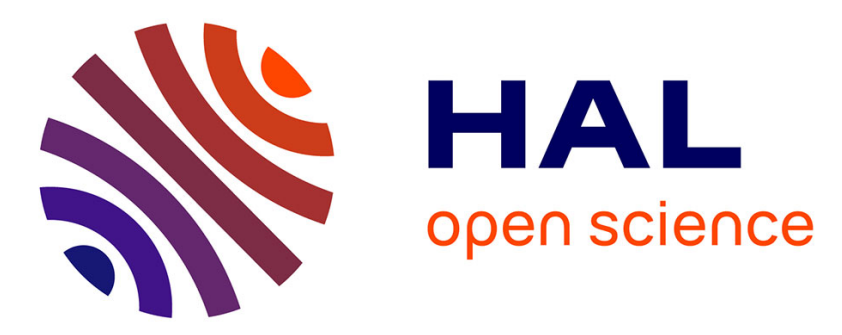

\title{
Variable temperature NMR of organogelators: the intensities of a single sample describe the full phase diagram
}

Elliot Christ, Dominique Collin, Jean-Philippe Lamps, Philippe Mesini

\section{- To cite this version:}

Elliot Christ, Dominique Collin, Jean-Philippe Lamps, Philippe Mesini. Variable temperature NMR of organogelators: the intensities of a single sample describe the full phase diagram. Physical Chemistry Chemical Physics, 2018, 20 (14), pp.9644-9650. 10.1039/C8CP00009C . hal-02352963

\section{HAL Id: hal-02352963 \\ https://hal.science/hal-02352963}

Submitted on 24 Nov 2020

HAL is a multi-disciplinary open access archive for the deposit and dissemination of scientific research documents, whether they are published or not. The documents may come from teaching and research institutions in France or abroad, or from public or private research centers.
L'archive ouverte pluridisciplinaire HAL, est destinée au dépôt et à la diffusion de documents scientifiques de niveau recherche, publiés ou non, émanant des établissements d'enseignement et de recherche français ou étrangers, des laboratoires publics ou privés. 


\title{
PCCP
}

\section{ARTICLE}

\section{Variable Temperature NMR of organogelators : the Intensities of a Single Sample Describe the Full Phase Diagram}

Received 00th January 20xx, Accepted 00th January 20xx

DOI: $10.1039 / \times 0 x \times 00000 x$

www.rsc.org/

\begin{abstract}
Elliot Christ, ${ }^{a}$ Dominique Collin, ${ }^{a}$ Jean-Philippe Lamps ${ }^{a}$ and Philippe J. Mésini ${ }^{\mathrm{a}, \mathrm{b}, *}$
Organogelators constitute a numerous class of compounds, able to form gels in organic solvents. The mechanisms of the formation of gels, the their stability are still poorly understood. The knowledge of their phase diagram is necessary to tackle such fundamental questions. We show that liquid NMR can simplify and quicken the acquisition of phase diagrams. In liquid NMR spectra of organogels, the visible signals of the gelator represent only its soluble fraction. The intensities increase with temperature, until the gel melts. When suitably normalized, they yield the solubility as a function of temperature and are sufficient to map the phase diagram. We verified it experimentally with three organogelators, chosen because independent authors have previously mapped out their phase diagram. We show that the curves obtained by NMR superimpose with the phase diagram mapped by DSC, rheology or other techniques. A variable temperature NMR experiment with a single sample can yield the phase diagram with sensitivity of the order of $0.01 \mathrm{wt}$. \%.
\end{abstract}

\section{Introduction}

Organogelators have become an increasing field of study in chemistry. ${ }^{1-10}$ These compounds are small molecules able to gel solvents at low concentration by forming fibrillar selfassemblies. Most efforts have been devoted to design and synthesize new gelators with functional properties and a large library of organogelators has been now constituted. But despite this large library of compound, there is still no rule to design a gelator de novo. The comparison of their phase diagram should be an asset to compare them and make them a more quantitative comparison. In the earlier literature on organogels, phase diagrams were systematically mapped out, but this task is now rarely undertaken. Moreover, the few phase diagrams mapped in the literature are generally studied in a narrow range of concentrations, typically half a decade. Indeed, the exploration of small concentration is limited by the sensitivity of the most common techniques, DSC and rheology. Especially, determination of the gel-to-sol transition temperatures by rheological methods requires that the elastic modulus $G^{\prime}$ is still measurable while the applied stress is below the yield stress. Since $G^{\prime}$ decreases when $c$ decreases, there is a detection threshold at low $c$ when the gels become too weak. DSC experiments measure the enthalpy of the selfassociation of the gelator during the transition. The technique

\footnotetext{
Institut Charles Sadron, Université de Strasbourg, 23 rue du Loess, BP 84047, 67034 Strasbourg Cedex.

${ }^{b}$. International Center for Frontier Research in Chemistry, 8 allée Gaspard Monge, 67000 Strasbourg.

Electronic Supplementary Information (ESI) available: Synthetic procedure for DDOA; experimental for NMR experiments; integrals of HSA and standard experimental for DSC and rheology experiments; measurements of the solubility at different temperatures. See DOI: 10.1039/x0xx00000x
}

also experiences a sensitivity threshold, depending on concentration and molar enthalpy. Regardless of these experimental limits, mapping out a phase diagram is tedious and lengthy because it necessitates measuring the melting temperature of samples at several concentrations.

NMR has seldom been implemented to map out phase diagrams. In organogels, the intensities of the signals of the gelators represent only a fraction of the total gelators amount. This fraction increases with $T$ and levels off when all gelator is in solution. The start temperature of the plateau is a measurement of $T_{\mathrm{m}}$. Terech mapped out the phase diagram of a gelator thanks to measurement. ${ }^{11}$ But with this technique, like with others, the phase diagrams requires for each point, the preparation of one samples with a distinct concentration and the measurement of its $T_{\mathrm{m}}$. In the gel, below $T_{\mathrm{m}}$, most of the gelator is silent because it belongs in the solid network and therefore the relaxation is very fast. Many authors have assigned the remaining intensity as the concentration of the gelator in the liquid phase. ${ }^{12-17}$ Hirst et $a l^{17}$ have measured the solubility of a gelator at different temperatures and have correlated it with the temperature of transitions. But no clear relation has been established between the NMR intensities measured in an organogel at different temperatures and the phase diagram.

We have measured the NMR intensities of three different organogels as a function of temperature. We have compared the intensities below the melting temperature with the phase diagrams mapped by other techniques. We show that the NMR intensities of a single sample relate simply to sol-gel boundary of its phase diagrams. This simplifies the acquisition of phase diagrams. 


\section{Experimental}

\section{Materials}

BHPB10 was synthesized according to a published procedure. ${ }^{18}$ HSA was purchased from Aldrich and used as is. DDOA was synthesized by a modified procedure from the literature ${ }^{19}$ (see ESI).

\section{Variable temperature NMR.}

The NMR spectra were measured at different temperatures on a Bruker Avance III spectrometer operating at $600 \mathrm{MHz}$. The temperature of the probe was calibrated by two methods: with a thermocouple inserted in a sample; from the shifts of methanol at different temperatures. ${ }^{20}$ both methods yielded the same temperatures within $\pm 0.4^{\circ} \mathrm{C}$.

In a typical experiment, the required amount of the gelator was weighed on a precision balance (accuracy $\pm 20 \mu \mathrm{g}$ ) in a NMR tube. A standard bis(trimethylsilyl)acetylene (BTMSA) was introduced by adding a weighed amount $(20 \mathrm{mg})$ of a solution in the deuterated solvent ( $2 \mathrm{wt}$. \% solution). The rest of the deuterated solvent (about $0.5 \mathrm{~mL}$ ) was weighed in the tube to match the desired wt. concentration.

The temperature was incremented by steps of 1 or $2^{\circ} \mathrm{C}$. After each heating steps, the sample temperature was allowed to stabilize and equal the targeted temperature within $\pm 0.1^{\circ} \mathrm{C}$, at least during $40 \mathrm{~s}$ and the sample was let equilibrate at this temperature for additional 3 to $4 \mathrm{~min}$. The FID were measured only after this delay. The overall heating rate was about 0.25 ${ }^{\circ} \mathrm{C} / \mathrm{min}$.

The recycling times and pulse angles were tuned to reach a good compromise between experiment duration and errors of integration. For instance, longitudinal relaxation times $T_{1}$ of the proton of HSA at $3.6 \mathrm{ppm}$ (Fig. 2) $T_{1}$ varies from 6.3 to $1.5 \mathrm{~s}$ when the temperature increases, and for the protons of the standard $T_{1}$ varies from 3.3 to $6.1 \mathrm{~s}$. The recycling time has been set at $18 \mathrm{~s}$ and the pulse angle of $30^{\circ}$. The resulting bias (less than $1 \%$ ) has been taken into account to estimate the overall errors (see below).

The measured intensities $I_{\mathrm{m}}$ were normalized to the integrals of the peaks of the standard $I_{\text {st }}$ (Fig. S1, ESI). The normalized intensities are noted $I\left(I=I_{\mathrm{m}} / I_{\mathrm{st}}\right)$. The intensities of several peaks of the gelator were measured either by direct integration, either by fitting the peaks with lorentzian functions. When the gel was melted, the intensities of the peaks reached a plateau. The values of the intensities of the plateau were averaged and the average value was taken as $I_{\max }$. The uncertainty on the average of the plateau estimated as the peak-to-peak deviation (about $2 \%$ ).

The intensities I of the peaks of the gelators were converted to the weight concentrations with eq. 1 .

$c=c_{t} \frac{I}{I_{\max }} /\left[1+c_{t}\left(\frac{I}{I_{\max }}-1\right)\right]$

where $c_{\mathrm{t}}$ is the total wt. concentration of the gelator, $I_{\max }$ is the averaged intensity of the peak in the plateau. $I_{\max }$ has been measured after averaging the intensities in the plateau. For low concentrations, c can be approximated by eq. 2 with an uncertainty less than $0.5 \%$.

$c=c_{t} \frac{I}{I_{\max }}$

Equal weight fractions in deuterated and protonated solvents do not represent the same molar concentration. Therefore, the plots mixing results in deuterated solvent with results in protonated solvent were represented with molar fractions in abscissa. The molar fractions $X$ were calculated form the NMR intensity according equation ( 3 )

$X=X_{t} \frac{I}{I_{\max }} /\left[1+X_{t}\left(\frac{I}{I_{\max }}-1\right)\right]$

where $X_{\mathrm{t}}$ is the total molar fraction. For low concentration $\mathrm{X}$ can be approximated by an equation similar to eq. 2 .

The calculation of the concentrations gave similar results with intensities measured by integrations or by fitting, within less than $1 \%$ error for higher temperatures and less than $5 \%$ for the lower temperatures. The uncertainty of $c$ or $X$ was appraised by taking into account the signal/noise ratio (SNR), the incomplete integration range $(\sim 2 \%),{ }^{21}$ the uncertainty on mass $(\sim 1 \%)$. The error due to SNR is about constant with temperature, therefore the uncertainty on the NMR intensities decreases from $1 \%$ at the plateau to large values at low $T$ and c. The lower concentrations with a high uncertainty (> $50 \%$ ) have been discarded.

DSC.

The thermograms were recorded with a SETARAM III microcalorimeter. The measuring cell was filled with a gelator/solvent mixture (between 100 and $200 \mathrm{mg}$ ). The reference cell was filled with a mass of pure solvent equal to that of the first cell within $0.1 \mathrm{mg}$. The gel was formed during a first cycle of heating at $1{ }^{\circ} \mathrm{C} / \mathrm{min}$ and cooling at $0.3^{\circ} \mathrm{C} / \mathrm{min}$. The thermograms were measured during a second cycle at heating and cooling rates close to the overall rate of the NMR experiments $\left(0.25^{\circ} \mathrm{C} / \mathrm{min}\right)$.

\section{Rheology}

The real and imaginary parts of the shear modulus were measured as a function of temperature as described previously. ${ }^{18}$ The temperature of gel-to-sol transition is defined by the temperature for which the elastic modulus $G^{\prime}$ and loss modulus $G^{\prime \prime}$ cross over. Each transition temperature was measured for decreasing stress values and the temperature was deduced from a null stress extrapolation. This caution avoids measuring a decrease of $G^{\prime}$ because it flows under a high stress.

\section{Results and discussions}

\section{Choice of the studied gelators}

In this study we have considered 3 examples of gelators (Chart 1) for which the phase diagrams are described in the literature: 


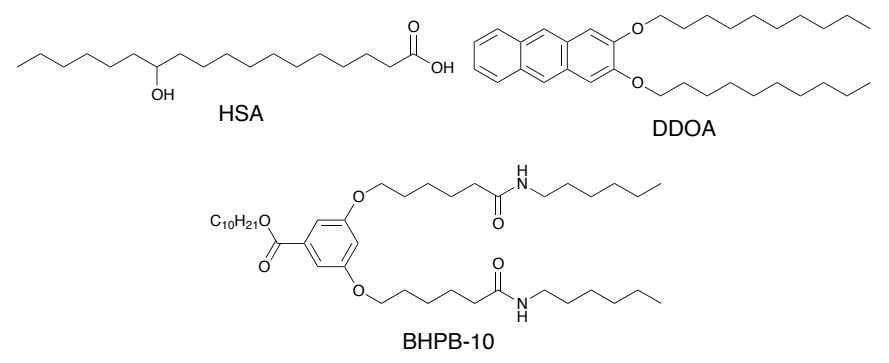

Chart 1 Structure of the studied organogelators.

hydroxystearic acid (HSA), 2,3-didecyloxyanthracene (DDOA) and decyl 3,5-bis((6-(hexylamino)-6-oxohexyl)oxy)benzoate (BHPB10).

Terech has mapped out the phase diagram of $\mathrm{HSA} /$ nitrobenzene by three techniques: NMR, mechanical measurements in a rheometer and the falling ball method. He also compared these techniques: there is a good agreement between the temperatures measured by the first two techniques (less than $2{ }^{\circ} \mathrm{C}$ ) but a gap $\left(>5^{\circ} \mathrm{C}\right)$ between them and those measured by the last method.

The phase diagram of DDOA has been established by Desvergne et al. ${ }^{19,20}$ by light transmission measurements, in many solvents, including solvents with deuterated equivalents. Lately we have established the phase diagram of BHPB-10 in trans-decalin (TD) by DSC, rheology, and light transmission. ${ }^{18}$ As we have shown by optical microscopy, the system experiences a miscibility gap at high concentrations, which results in a monotectic transformation. The gelation of HSA and BHPB10 involves $\mathrm{H}$-bonds, but the gelation of DDOA involves only van der Waals interactions especially pi-stacking. We have studied the following gelator/solvent systems: HSA/nitrobenzene; BHPB10/TD; DDOA/EtOH.

\section{Aspect of the spectra}

As an example, the spectra of HSA are displayed (Fig. 1). They were measured while temperature varies from $25^{\circ} \mathrm{C}$ to $75^{\circ} \mathrm{C}$, passing the melting temperature of the gel $T_{\mathrm{m}}$ at $52.5{ }^{\circ} \mathrm{C}$ (as measured by DSC).

The intensities of the signals of the gelators were normalized to the intensities of an internal standard

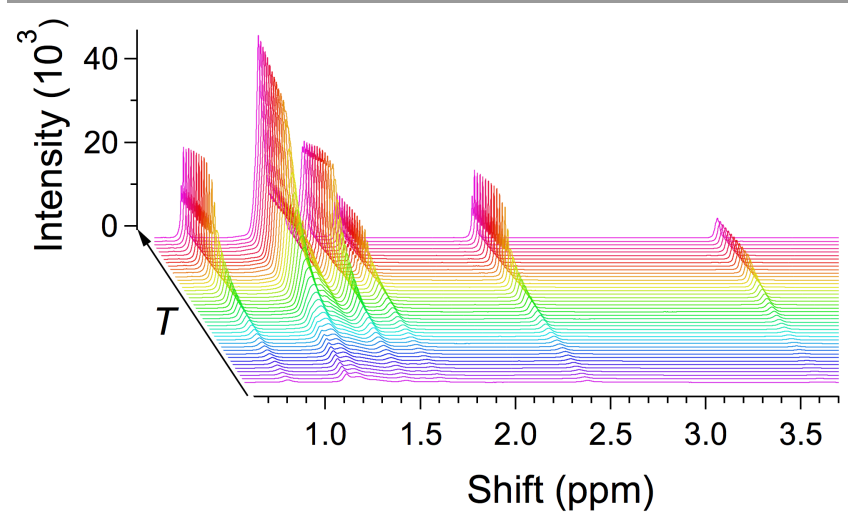

Fig. 1 NMR Spectra of HSA in d5-nitrobenzene (4 wt. \%), from 25 to $100{ }^{\circ} \mathrm{C}$.
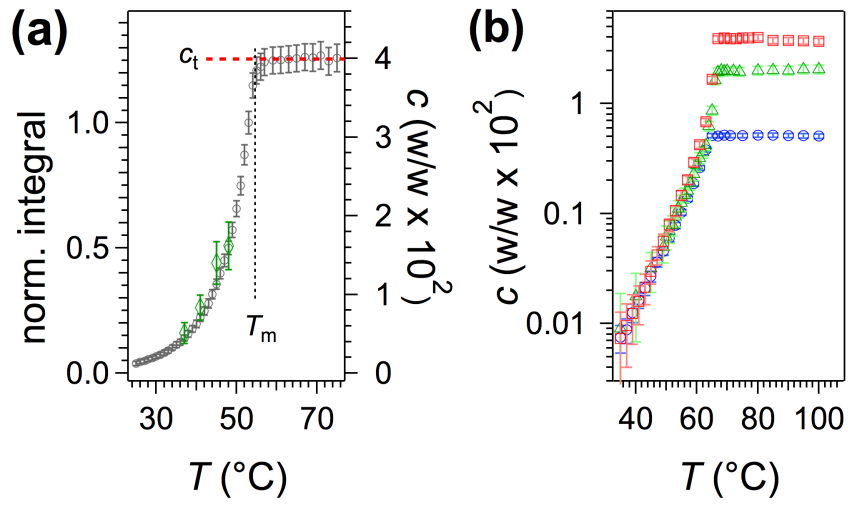

Fig. 2 a) VT-NMR of HSA/d5-nitrobenzene. Integrals of the $\mathrm{CHOH}$ peak vs $T(O)$. The integrals are normalized to the intensities of an internal standard (BTMSA); the solubility of HSA were measured according with ref $17(\diamond)$. Right axis: corresponding wt. concentrations, calculated from equ. $1 ; T_{\mathrm{m}}=54.6{ }^{\circ} \mathrm{C}\left(T_{\mathrm{DSC}}=52.5^{\circ} \mathrm{C}\right)$. b) conc. calculated from NMR intensities (Eq. 1) during heating of BHPB10/d18-TD at 0.5 ( $\square$ ), 2 $(\triangle)$ and 4 wt. \% (O).

(Fig. S1, ESI). Fig. 2a represents the normalized intensities I of the signal at $3.6 \mathrm{ppm}(\mathrm{CHOH}) . l$ increases with $T$ and reaches a plateau $I_{\max }$ at a temperature that can be taken as a measurement of the melting temperature $T_{\mathrm{m}}$, as in the work by Terech. ${ }^{11}$ The found value in our example is $54.6^{\circ} \mathrm{C}$, close to that measured by DSC.

The height of the plateau corresponds to the total concentration of gelator $c_{\mathrm{t}}$. The intensities below $T_{\mathrm{m}}$ were normalized to this height to convert the integrals to wt. concentrations (Eq. 1) or to molar fractions (Eq. 3). In this representation, the ascending branch of the curve quantifies the fraction of gelator not silent in NMR.

\section{Assignment of the intensities below $T_{m}$}

In the literature, the signals observed by NMR in a gel have been assigned to the fraction of gelator in solution. ${ }^{12-17}$ This fraction includes free molecules, associated molecules and excludes the gelator in the solid phase. Several arguments support this assignment. At room temperature, in a series of samples with increasing concentrations of gelator, the NMR intensities increase below gel concentration and correspond to the concentration of gelator; above gel concentration, the intensities plateau. ${ }^{16,17}$ The shifts of labile protons, as in amides, also support this interpretation: the shifts of those protons often increase with $T .^{18}$ It shows the proportion of $\mathrm{H}$ bonded groups increases. This can be explained by the increase of concentration with soluble gelator with $T$, which favors intermolecular $\mathrm{H}$-bonds. According to other authors, ${ }^{13}$ the visible signal includes also a part of the solid network, which has a mobility sufficient to allow its detection. This interpretation is based on a decrease of the relaxation time of the signal of the gelators in the gel phase. However Escuder et al. ${ }^{16}$ have observed similar decrease with free monomeric gelators and explained it by a dynamic exchange of the gelator in the solvent and the solid.

In this work, we also assign the NMR signal below $T_{\mathrm{m}}$ to the soluble fraction of gelator. This is supported by the variations of the NMR signal for various concentrations of gelator. Fig $2 b$ 
gives the example of the intensities measured in gels of BHPB10 at three different total concentrations in a large range (the highest is 8 times the smallest). For all experiments, the intensities below the different values of $T_{\mathrm{m}}$ superimpose. Only the height of the plateau varies when the total concentration $c_{t}$ varies. Then, the intensities of the signal in the ascending branch do not depend on the amount of gel, but on temperature only. It proves that below $T_{m}$, the observed signal do not belong to the solid fraction of the gel, but is related only to the soluble fraction.

This signal can be related explicitly to solubility. Smith et $a l^{17}$ have determined the solubility of gelators by NMR and have correlated it with phase diagrams. We have measured the solubility of HSA by their method: samples at different concentrations of gelator $c_{t}$ have been prepared. For a given temperature, the NMR intensities for each sample have been measured, calibrated with an internal standard and plotted vs $c_{\mathrm{t}}$ (Fig. S2, ESI). The measured conc. increases with $c_{\mathrm{t}}$ and reaches a plateau at a concentration which is taken as the solubility value. The solubility values measured by this method at different temperatures follow the concentrations measured in a single gel by our method (Fig 2a). In conclusion, the concentrations calculated from the measured intensities through equ. (1) or (2) are a good approximation of the solubility (eq. 3 )

$$
s(T)=c \approx \frac{I}{I_{\max }} c_{t}
$$

where $s(T)$ is the solubility as a function of $\mathrm{T}$.

\section{Relationship between the measured intensities and the phase diagram.}

For each given conc. $c_{t}$, the starting point of the plateau has $\left(T_{m}, c_{\mathrm{t}}\right)$ as coordinates, and when $c_{\mathrm{t}}$ varies, the starting point moves along the master curve (Fig 2a). Therefore the master curve represents $c_{\mathrm{t}}=\mathrm{f}\left(T_{\mathrm{m}}\right)$ and is the boundary between sol and gel in the phase diagram. The relationship between the intensities measured by NMR and the phase diagram can be established more formally: if one assumes that the NMR signal measures the soluble fraction of gelator, it measures its concentration in the liquid phase at equilibrium with the solid phase in the gel. By definition, it is the solubility and the boundary between two domains of the phase diagram : the liquid phase and the gel (= liquid + solid). The usual representation of the diagram, with $c$ as the abscissa, is yielded by inversion of the plot $(T=f(c))$.

We have verified this simple relation with the phase diagrams of HSA, BHPB10 and DDOA (Fig. 3). We have mapped out the phase diagrams by DSC and rheology experiments (suppl. info). The expermients were preformed at heating rate close to the rate of NMR experiments $\left(0.25{ }^{\circ} \mathrm{C} / \mathrm{min}\right)$. For the rheological mesurements, we applied different stress values $\sigma$, and we have extrapolated the melting temperature at low values of $\sigma$. Indeed, when $\sigma$ is higher than the yield stress, the gel flows below the real melting temperature. With the techniques of tube inversion or falling ball, the applied stress cannot be
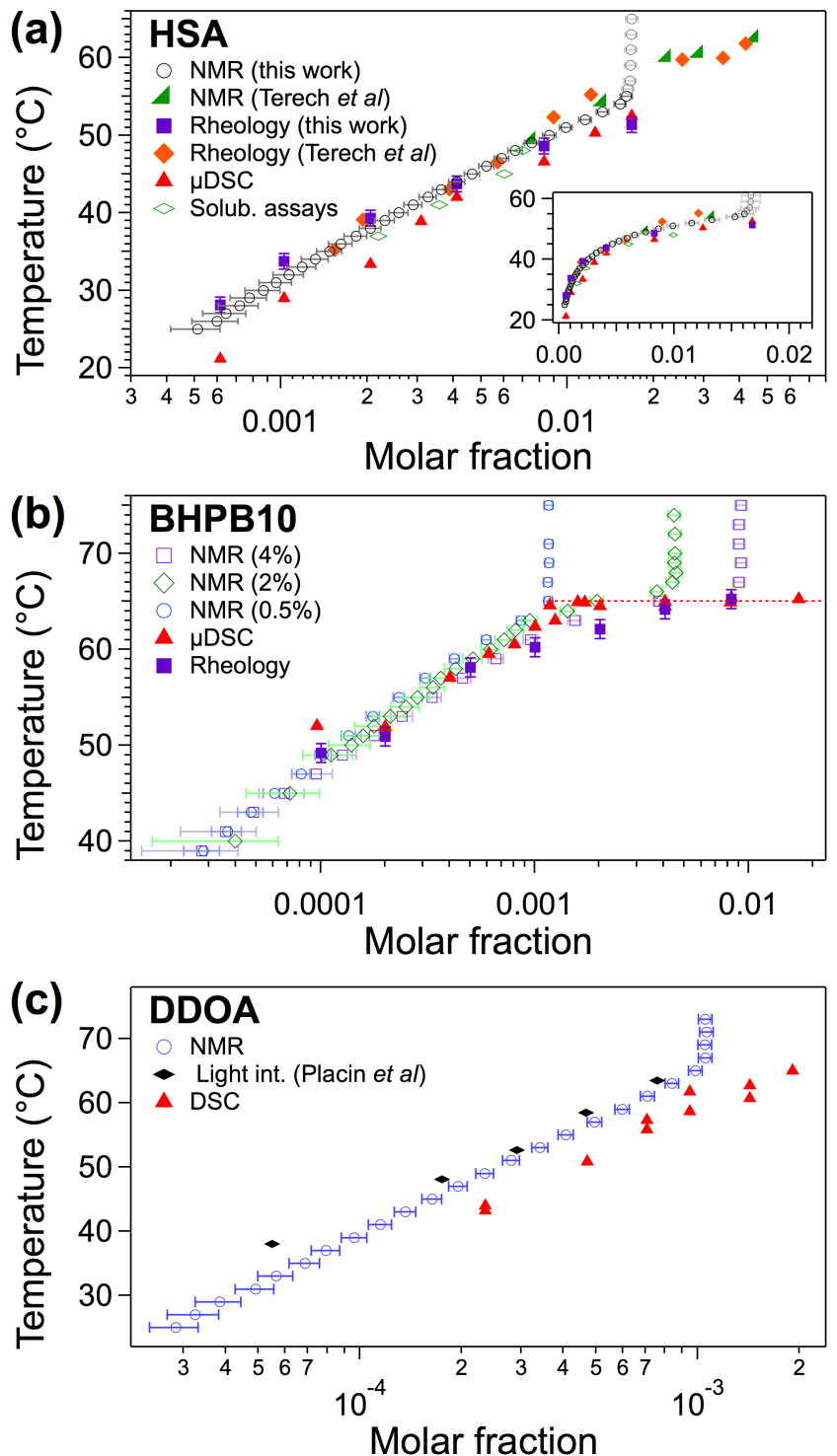

Fig. 3 Reverse plot of the molar fractions measured by NMR ( $T$ vs. $C$ ) superimposed on the phase diagrams mapped out with other techniques a) HSA; cited work: ref 11 ; inset: same diagram in linear scale; b) BHPB10; c) DDOA; cited work: refs 18 and 19. The vertical plateaus have been shortened for clarity (they do not define any boundary in the diagram). For (a) and (b), the NMR curves are the same as in Fig. $2 a$ and $2 b$, with the concentration converted in molar fractions.

tuned, which biases the values of the temperatures, at low concentrations. ${ }^{11,21}$

For HSA (Fig. 3a), our measurements by rheology agree with the Terech' $s$ results from NMR and rheology ${ }^{11}$ (also reported on the diagram) within less than $2{ }^{\circ} \mathrm{C} . T_{\mathrm{m}}$ values measured by DSC match those measured by rheology within a gap of ca $5^{\circ} \mathrm{C}$ (less than $2{ }^{\circ} \mathrm{C}$ for mol. fract. > than 0.03 ). In summary the phase diagram is carefully established by 3 techniques and 4 convergent sets of values. The $c$ values measured by NMR from Fig. 2 superimpose with this phase diagram, especially with the results obtained by rheology. It also matches the values obtained by Terech by NMR. But our NMR experiment differs from Terech's: he measured $T_{\mathrm{m}}$ as the start point of the 
plateaus in samples at different $c_{\mathrm{t}}$, whereas we measure the intensities below $T_{\mathrm{m}}$ for a single sample at one $c_{\mathrm{t}}$.

For BHPB-10, the phase diagram was mapped out by DSC and rheology (Fig 3b). The NMR intensities for various total concentrations superimpose with the phase diagram with an error less than $2{ }^{\circ} \mathrm{C}$. Above a given value of the total concentration, $T_{\mathrm{m}}$ reach a plateau. According to our previous work, ${ }^{18}$ it corresponds to a monotectic transformation, because above this threshold, the melted gelator and the solvent are not miscible. The NMR intensities correctly reproduce this plateau by a sudden jump of the intensities before the plateau (Fig 2b). The NMR intensities for DDOA (Fig. 3c) also follow correctly the phase diagram established by Desvergne et al. $^{20}$

In conclusion, the intensities of the gelators below $T_{\mathrm{m}}$ measure the solubility of the gelator and reproduce the phase diagram. Smith et al have established a correlation between the solubility of gelators and the sol-gel transition temperatures in a $c-T$ phase diagram. In fact both curves are the same.

When the transition temperatures exhibit a plateau, it is due to a liquid-liquid phase separation in the melt, ${ }^{18}$ which makes the transition non-variant. Therefore this part of the curve is no longer correlated to solubility.

NMR measures the phase diagram faster and with more points than other methods. Our experiments by rheology or microDSC, with similar heating rates, take more than two weeks, for 6 to 10 points. A regular DSC, operating at higher heating rates measures $T_{\mathrm{m}}$ faster, but the measured values of should be extrapolated at null rate.

\section{Measured range and accuracy of the technique.}

The assignment of the signal requires that all the soluble species are visible in NMR and that the invisible species belong only in the solid phase. Especially large and yet soluble aggregates may have broadened signals hard to detect or integrate and may be source of errors. However the match between NMR and other techniques suggest that it is negligible. Moreover, in the literature, such large aggregates have been ruled out in several cases. For instance, some organogelators do not self-associate in the liquid phase. ${ }^{16}$ When aggregation is cooperative above a threshold degree of aggregation, the aggregates becomes infinite and are integrated in the solid fraction. ${ }^{17}$

The rate of heating must be very slow to equilibrate the system. Since $T$ is increased by discrete steps, it is necessary to proceed with small increments and wait, even after the temperature is stabilized for each spectrum.

The recycling times and pulse angles have been set to limit the errors on integrals, but the main uncertainty of the measured integrals is due to the signal/noise ratio (SNR), especially at low temperatures. As seen before, the intensities of the signals do not increase with $c_{\mathrm{t}}$. Therefore the SNR can be improved only by increasing the number of scans for each step. The observable range of concentration is limited to the detection of the peaks at low temperature, and the measurement of its area with an acceptable error. With a standard spectrometer, we found a minimal concentration of the order of $0.01 \mathrm{wt}$ \%, which is below the sensitivity threshold by DSC or rheology. However, DSC remains necessary to prove that the domain solid +liquid is mechanically a gel.

Soluble impurity with shifts close to those of the observed peaks may bias the integration. The concentration of the impurity is constant while the concentration in soluble gelator decreases with $T$. The bias is detectable by an apparent floor value at low $T$, which limits the $c$-range. For instan ce, a bias of less than $10 \%$ over two decades of $c$, requires an impurities $/ c_{t}$ ratio lower than $0.1 \%$. The effect of impurities can be overcome by considering other peaks in the spectrum or by repeating the experiment with lower $c_{\mathrm{t}}$ value and superimposing the curves from the experiments at both $c_{t}$ values.

In summary, if the heating rate is slow, the compound sufficiently pure and the recycling time long enough, the method measures routinely at least one and half decade of $c$ below the nominal concentration $c_{t}$ a few wt. \% and on a single sample. For the lower $c$ values, accuracy is limited by the SNR and uncertainty can reach several 10 s of percent; but in the first decade below $c_{t}$, the uncertainty is routinely a few percent.

\section{Study under cooling.}

The intensities have been measured in the same samples also while they were cooled and normalized as described above. For HSA, the cooling curve follows the sol-to-gel temperatures, except a small hysteresis between 55 and $50{ }^{\circ} \mathrm{C}$ (Fig. 4a). This hysteresis is more evident for BHPB-10 (Fig. 4b) and can be interpreted more easily because we had previoulsly ${ }^{18}$ mapped out the phase diagram upon cooling. Diagrams upon heating and cooling have the same aspect, except the temperatures of gel formation $T_{\mathrm{g}}$ are lower than the temperature of melting $T_{\mathrm{m}}$. When the solution is cooled, $c$ values measured by NMR keep constant at a temperature lower than $T_{\mathrm{m}}$. When $T$ reaches $T_{\mathrm{g}}$, they drop to the $c$ values measured upon heating, and keep close to them when $T$ further decreases. This can be explained easily: above $T_{m}$, all the gelator is in solution and its concentration is constant. When $T_{\mathrm{g}}<T<T_{\mathrm{m}}$, the gelator is still in solution, but the solution is now metastable. The gel forms only at $T=T_{\mathrm{g}}$. The gelator is removed from the solution and incorporated into the solid phase, which decreases the gelator concentration visible by NMR. It diminishes abruptly until it reaches the solubility of gelator, that is, the sol-gel boundary at equilibrium. For lower $T, c$ falls or borders on the sol-gel line.

The cooling curves follow the hysteresis observed by other techniques and are coherent with the nucleation-growth mechanism previously observed for the gelation of BHPB10. ${ }^{18}$ However the cooling curves poorly ascribe the phase diagram. First, they show the sol-gel-line only below $T_{\mathrm{g}}$. Second, the cooling curves do not superimpose closely with the sol-to-gel line at all $c_{\mathrm{t}}$ values. For DDOA, the gap between cooling and the heating curves is higher (Fig. 4c). The measured concentrations decrease gradually and before $T$ reaches the temperature of gel measured by DSC. It suggests a slower 

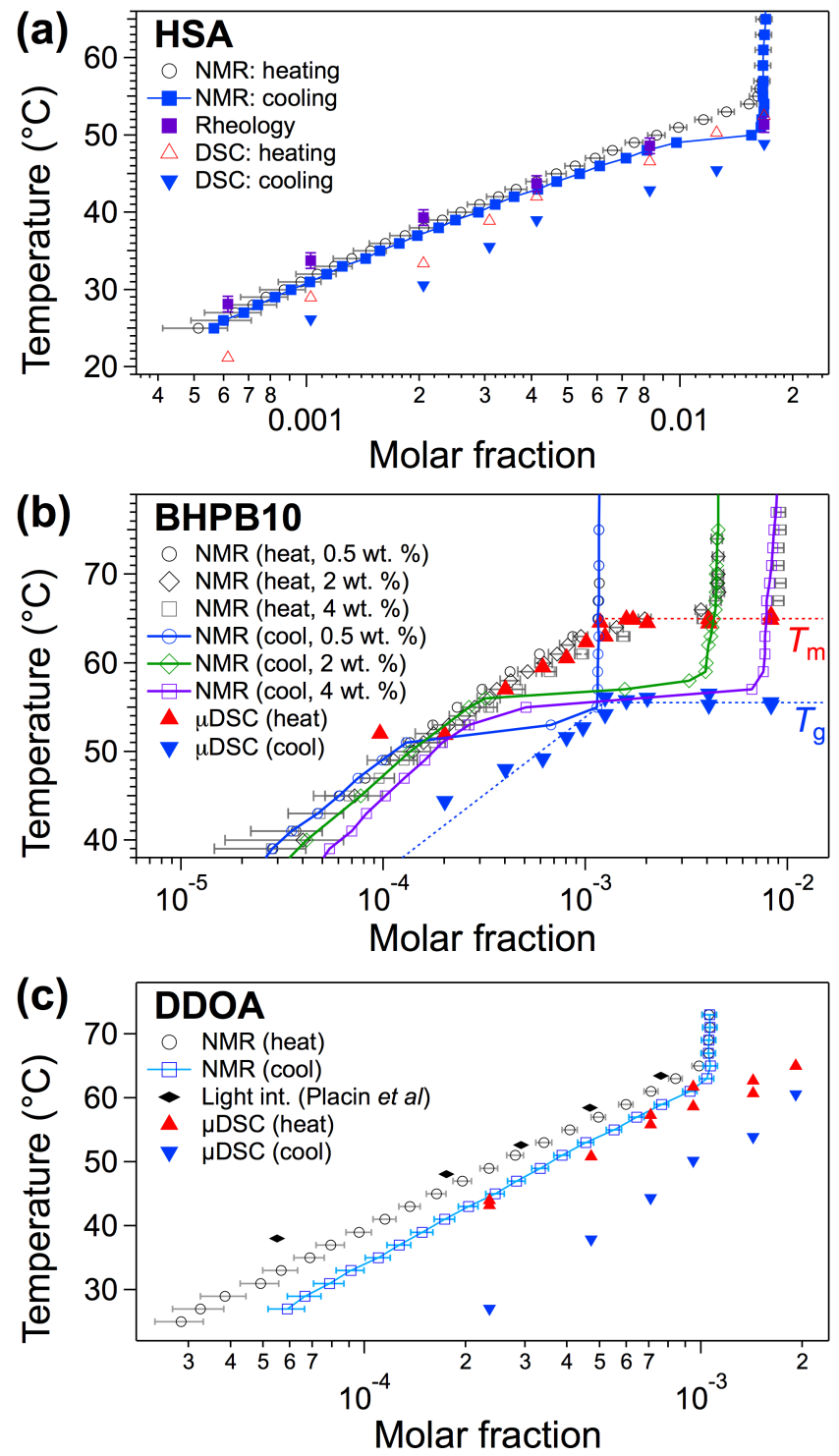

Fig. 4 Molar fraction measured by NMR during cooling and comparison with other data a) HSA; b) BHPB10; c) DDOA. For clarity the error bars of the cooling curves of HSA and BHPB10 have been omitted.

mechanism of gelation. In summary, the cooling curves represent only a rough approximation of the sol-to-gel line, because they are strongly influenced by the kinetics and mechanism of gel formation.

\section{Conclusion}

In agreement with previous work, we prove that the visible signal corresponds to the soluble fraction of the gelator. In variable temperature experiments, the intensities of this signal, when normalized to $I_{\max } / c_{\mathrm{t}}$ equal the solubility $s(T)$ of the gelator with a good approximation; the curve representing $T=\mathrm{f}(s)$ defines the sol-gel boundary in the phase diagram. We have proved it experimentally by superimposing the phase diagram mapped out by other techniques.

Therefore it is possible to draw the gel-to-sol boundary with a single sample and avoid the measurements of $T_{\mathrm{m}}$ on many samples, unlike with other techniques. The sensitivity of the technique depends only on the signal/noise ration of the NMR, that is the accumulation time at each temperature. The explored concentration range is one and half decades typically from $\sim 1$ wt. $\%$ to $\sim 0.05$ wt. $\%$ on a $600 \mathrm{MHz}$ spectrometer, with an acceptable uncertainty.

The cooling curves cannot be implemented to map out the phase diagram, because they are subject hysteresis. They also reflect the kinetics of formation of the gel.

\section{Conflicts of interest}

There are no conflicts to declare.

\section{Acknowledgements}

This work was funded by the Ministère de l'Education Nationale et de l'Enseignement Supérieur (Fellowship ED 182, 2014-045 for E. C.) and by the International program of the Agence National de la Recherche and the Indo-French Centre for the Promotion of Advanced Research IFCPAR-CEFIPRA (DST)-ANR (Grant 14-CE08-0020-01). We thank L. Allouche and B. Vincent and the NMR facility (facility of chemical analysis, GDS 2648, University of Strasbourg) for the NMR experiments and for helpful discussions. We acknowledge the characterization facilities for the use of the micro-DSC and Cathy Saettel for her help.

\section{Notes and references}

1 P. Terech and R. G. Weiss, Chem. Rev., 1997, 97, 3133-3160.

2 J. H. Van Esch and B. L. Feringa, Angew. Chem., Int. Ed., 2000, 39, 2263-2266.

3 L. A. Estroff and A. D. Hamilton, Chem. Rev., 2004, 104, 120118.

4 F. Fages, Ed., Low Molecular Mass Gelators - Design, SelfAssembly, Function, Springer Berlin Heidelberg, Berlin, Heidelberg, 2005, vol. 256.

5 N. M. Sangeetha and U. Maitra, Chem. Soc. Rev., 2005, 34, 82136.

6 R. G. Weiss and P. Terech, Molecular gels. Materials with selfassembled Fibrillar Network, Springer, Dordrecht, The Netherlands, 2006.

7 A. R. Hirst, B. Escuder, J. F. Miravet and D. K. Smith, Angew. Chem. Int. Ed., 2008, 47, 8002-8018.

8 B. Escuder, F. Rodríguez-Llansola and J. F. Miravet, New J. Chem., 2010, 34, 1044-1054.

9 S. S. Babu, V. K. Praveen and A. Ajayaghosh, Chem. Rev., 2014, 114, 1973-2129.

10 R. G. Weiss, J. Am. Chem. Soc., 2014, 136, 7519-7530.

11 P. Terech, C. Rossat and F. Volino, J. Coll. Interf. Sci., 2000, 227, 363-370.

12 F. M. Menger, Y. Yamasaki, K. K. Catlin and T. Nishimi, Angew. Chem. Int. Ed., 1995, 34, 585-586.

13 D. C. Duncan and D. G. Whitten, Langmuir, 2000, 16, 64456452. 
14 J. Makarević, M. Jokić, Z. Raza, Z. Štefanić, B. Kojić-Prodić and M. Žinić, Chem. Eur. J., 2003, 9, 5567-5580.

15 D. Rizkov, J. Gun, O. Lev, R. Sicsic and A. Melman, Langmuir, 2005, 21, 12130-12138.

16 B. Escuder, M. LLusar and J. F. Miravet, J. Org. Chem., 2006, 71, 7747-7752.

17 A. R. Hirst, I. A. Coates, T. R. Boucheteau, J. F. Miravet, B. Escuder, V. Castelletto, I. W. Hamley and D. K. Smith, J. Am. Chem. Soc., 2008, 130, 9113-21.

18 E. Christ, C. Blanc, A. Al Ouahabi, D. Maurin, R. Le Parc, J.-L. Bantignies, J.-M. Guenet, D. Collin and P. J. Mésini, Langmuir, 2016, 32, 4975-4982.

19 F. Placin, J. P. Desvergne and J. C. Lassegues, Chem. Mater., 2001, 13, 117-121.

20 J.-P. Desvergne, T. Brotin, D. Meerschaut, G. Clavier, F. Placin, J.L. Pozzo and H. Bouas-Laurent, New J. Chem., 2004, 28, 234243.

21 S. R. Raghavan and B. H. Cipriano, in Molecular Gels, eds. R. G. Weiss and P. Terech, Springer Netherlands, 2006, pp. 241-252. 


\title{
Variable Temperature NMR of organogelators : the Intensities of a Single Sample Describe the Full Phase Diagram
}

\author{
Elliot Christ, ${ }^{a}$ Dominique Collin, ${ }^{a}$ Jean-Philippe Lamps ${ }^{a}$ and Philippe J. Mésini ${ }^{\mathrm{a}, \mathrm{b}, *}$
}

\section{Electronic Supplementary Information}

\section{Synthesis of DDOA}

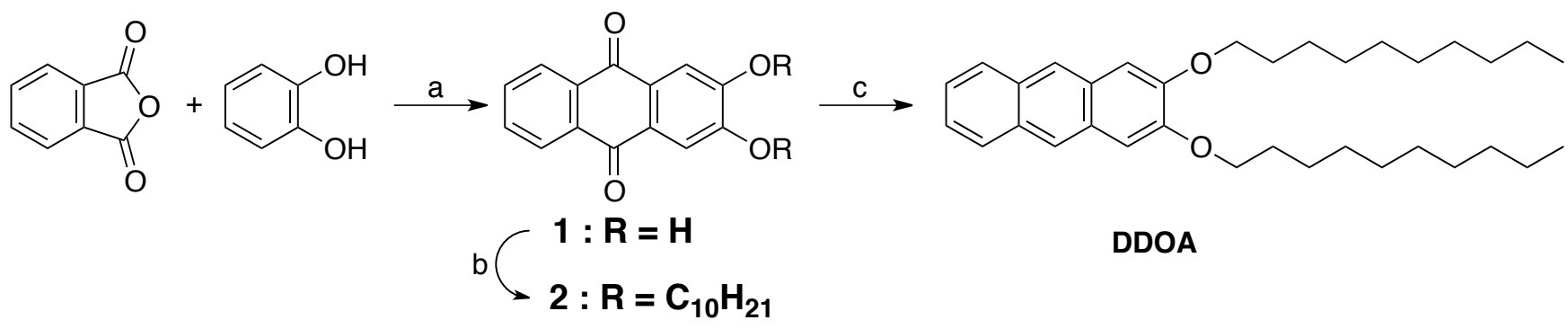

Scheme 1. Synthetic scheme. a) $\mathrm{AICl} 3,120^{\circ} \mathrm{C}, 30 \%$; b) $\mathrm{C}_{10} \mathrm{H}_{21} \mathrm{OSO}_{2} \mathrm{CH}_{3}, \mathrm{~K}_{2} \mathrm{CO}_{3}, \mathrm{Bu}_{4} \mathrm{NBr}, \mathrm{DMF}, 55 \%$; c) $\mathrm{Zn}, 40 \%$.

2,3-dihydroxyanthracene-9,10-dione (1). $\mathrm{AlCl}_{3}(100 \mathrm{~g}, 750 \mathrm{mmol})$ and $\mathrm{NaCl}(13 \mathrm{~g}, 222 \mathrm{mmol})$ were heated at $120{ }^{\circ} \mathrm{C}$ under mechanical stirring until the formation of the eutectic liquid. 1,2-Dihydroxybenzene $(11.1 \mathrm{~g}, 101 \mathrm{mmol})$ and phtalic anhydride $(15.0 \mathrm{~g}, 101 \mathrm{mmol})$ were added over 30 minutes and the solution was heated at $150{ }^{\circ} \mathrm{C}$ for $1 \mathrm{~h} 30$. The reaction mixture was cooled and hydrolyzed with water first (150 ml) and then with hydrochloric acid $(37 \%, 200 \mathrm{ml})$. The suspension was dissolved by reflux $\left(160^{\circ} \mathrm{C}\right)$ for $3 \mathrm{~h}$. On cooling, a brown solid precipitated. It was filtered and dried under vacuum overnight. The precipitate was dissolved in sulfuric acid $95 \%(140 \mathrm{ml})$ and refluxed for $3 \mathrm{~h}$. The solution was cooled mixed with water $(300 \mathrm{~mL})$ and the resulting precipitate filtered off and dried overnight under vacuum. The crude recrystallized in acetic acid to afford 1 as a black powder and used without further purification. $(7.30$ g, yield $30 \%)$. M.p. $>270{ }^{\circ} \mathrm{C}\left(\operatorname{lit}^{1} 393-394^{\circ} \mathrm{C}\right) ;{ }^{1} \mathrm{H} \mathrm{NMR}\left(\left(\mathrm{CD}_{3}\right)_{2} \mathrm{SO}, 400 \mathrm{MHz}\right)$ : $\delta 10.65$, (br s, OH), $8.18(\mathrm{~d}, 2 \mathrm{H}, \mathrm{J}=5.9 \mathrm{~Hz}, 3.3 \mathrm{~Hz}, 5-\mathrm{H}$ and $8-\mathrm{H}), 7.90(\mathrm{~m}, 2 \mathrm{H}, \mathrm{J}=5.9 \mathrm{~Hz}, 3.3 \mathrm{~Hz}, 6-\mathrm{H}$ and $7-\mathrm{H}), 7.57(\mathrm{~s}, 2 \mathrm{H}, 1-\mathrm{H}$ and $4-\mathrm{H}) ;{ }^{13} \mathrm{C} \mathrm{NMR}$ $\left(\left(\mathrm{CD}_{3}\right)_{2} \mathrm{SO}, 100 \mathrm{MHz}\right): \delta 182.1$ (C10, C9), 153.2 (C2, C3), 134.5 (C6, C7), 133.9 (C8a, C10a), 127.5 (C4a, C9a), 127.0 (C5, C8), 114.2 (C1, C4). FTIR (neat, ATR): $v_{\max }\left(\mathrm{cm}^{-1}\right) 3456$ (br, s, vOH), 3207 (br, s, vC-OH), 1672 (s, vCO), 1575 (vCC aromatic), 1517, 1312, 1112, 971, 900, 793, 709; HRMS (ESI+): 241.0521, $\mathrm{M}+\mathrm{H}^{+}\left(\mathrm{C}_{14} \mathrm{H}_{8} \mathrm{O}_{4}\right.$ requires 240.0495).

2,3-bis(decyloxy)anthracene-9,10-dione (2): A solution of 1 (1.01 g, $6.35 \mathrm{mmol}), \mathrm{C}_{10} \mathrm{H}_{21} \mathrm{OSO}_{2} \mathrm{CH}_{3}(2 \mathrm{~g}, 12.7 \mathrm{mmol}, 2$ equiv.) and Bu $4 \mathrm{NBr}(680$ $\mathrm{mg}, 3.15 \mathrm{mmol}, 0.50$ equiv.) in DMF (100 mL) was stirred at $60{ }^{\circ} \mathrm{C}$ and $\mathrm{K}_{2} \mathrm{CO}_{3}(2.93 \mathrm{~g}, 21.1 \mathrm{mmol}, 3.32$ equiv.) was added slowly. The reaction was stirred for $12 \mathrm{~h}$ at $60{ }^{\circ} \mathrm{C}$, cooled at RT and mixed with aqueous $\mathrm{HCl}(1 \mathrm{M}, 1 \mathrm{~L})$. The resulting precipitate was recovered by filtration and purified by chromatography $\left(\mathrm{SiO}_{2}, \mathrm{CH}_{2} \mathrm{Cl}_{2} /\right.$ heptane : $\left.2 / 1\right)$ to afford pure 2 as a yellow powder $\left(1.21 \mathrm{~g}, 55 \%\right.$ yield). M.p. $100{ }^{\circ} \mathrm{C}\left(\right.$ lit $\left.{ }^{(1)} 101^{\circ} \mathrm{C}\right) ;{ }^{1} \mathrm{H} \mathrm{NMR}(400$ $\left.\mathrm{MHz}, \mathrm{CDCl}_{3}\right): \delta 8.26(2 \mathrm{H}, \mathrm{dd}, J=5.9 \mathrm{~Hz}, 3.3 \mathrm{~Hz}, \mathrm{C} 8, \mathrm{C} 5), 7.74(2 \mathrm{H}, \mathrm{dd}, J=5.9 \mathrm{~Hz}, 3.3 \mathrm{~Hz}, \mathrm{C} 6, \mathrm{C} 7), 7.68(2 \mathrm{H}, \mathrm{s}, \mathrm{C} 1, \mathrm{C} 4), 4.20(4 \mathrm{H}, \mathrm{t}, J=6.6 \mathrm{~Hz}, \mathrm{OCH})$, $1.89\left(4 \mathrm{H}, \mathrm{p}, J=7.2 \mathrm{~Hz}, \mathrm{OCH}_{2} \mathrm{CH}_{2}\right), 1.50\left(4 \mathrm{H}, \mathrm{m}, \mathrm{OCH}_{2} \mathrm{CH}_{2} \mathrm{CH}_{2}\right), 1.43-1.21\left(24 \mathrm{H}, \mathrm{m}, \mathrm{OCH}_{2} \mathrm{CH}_{2} \mathrm{CH}_{2}\left(\mathrm{CH}_{2}\right)_{6} \mathrm{CH}_{3}\right), 0.88(6 \mathrm{H}, \mathrm{t}, J=7.0 \mathrm{~Hz}, \mathrm{CH}) .{ }^{13} \mathrm{C}(100 \mathrm{MHz}$, $\mathrm{CDCl}_{3}$ ) : $\delta 182.6$ (C9, C10), 153.8 (C2, C3), 133.7 (C6, C7), 133.69 (C8a, C10a), 128.1 (C9a, C4a), 126.9 (C8, C5) 109.3 (C1, C4), 69.4 (OCH $), 31.9$ $\left(\mathrm{OCH}_{2} \mathrm{CH}_{2}\right), 29.7,29.6,29.5,29.4,28.9,26.0\left(\mathrm{CH}_{2} \mathrm{CH}_{2} \mathrm{CH}_{3}\right), 22.7\left(\mathrm{CH}_{2} \mathrm{CH}_{3}\right), 14.1\left(\mathrm{CH}_{3}\right)$. FTIR (neat, ATR diamond): $v_{\max }\left(\mathrm{cm}^{-1}\right) 3070,2917\left(\mathrm{v}_{\text {as }} \mathrm{CH}_{2}\right.$ alkyl), $2849\left(v_{s} \mathrm{CH}_{2}\right.$ alkyl), 1689 ( $\left.v_{\mathrm{s}} \mathrm{CO}\right), 1574$ (vCC aromatic), 1513, 1466, 1377, 1307, 1219, 1111, 1087, 885, 711, 621. HRMS (ESI+): 521.3641 $\mathrm{M}+\mathrm{H}^{+}\left(\mathrm{C}_{34} \mathrm{H}_{48} \mathrm{O}_{4}\right.$ requires 520.3625). Anal. Found: $\mathrm{C}, 78.48 ; \mathrm{H}, 9.33$. Calcd. for $\mathrm{C}_{34} \mathrm{H}_{48} \mathrm{O}_{4}: \mathrm{C}, 78.4 ; \mathrm{H}, 9.29$.

2,3-bis(decyloxy)anthracene (DDOA) : anthraquinone 2 (550 mg, $1.06 \mathrm{mmol})$, zinc powder (1.40 g, $21.4 \mathrm{mmol}, 20.2$ equiv.) and aqueous $\mathrm{NaOH}$ $(10 \%, 50 \mathrm{ml})$ were heated at $100{ }^{\circ} \mathrm{C}$ for $24 \mathrm{~h}$. The solution was cooled, filtered to remove the powder and extracted with dichloromethane $(2 \times 75$ $\mathrm{mL})$. The organic layer was dried $\left(\mathrm{Na}_{2} \mathrm{SO}_{4}\right)$ and concentrated under vacuum. The crude solid was purified by column chromatography $\left(\mathrm{C}_{6} \mathrm{H}_{12} /\right.$ EtOAc 9/1) to afford pure DDOA as a white powder $\left(207 \mathrm{mg}, 40 \%\right.$ yield). M.p. $85^{\circ} \mathrm{C}\left(\right.$ lit $\left.{ }^{(1)} 84^{\circ} \mathrm{C}\right) ; \mathrm{NMR}^{1} \mathrm{H}(400 \mathrm{MHz}, \mathrm{CDCl} 3): \delta 8.16(\mathrm{H}, \mathrm{s}, \mathrm{C} 9$, C10), $7.89(2 \mathrm{H}, \mathrm{dd}, J=6.4 \mathrm{~Hz}, 3.2 \mathrm{~Hz}, \mathrm{C} 8, \mathrm{C} 5), 7.37(2 \mathrm{H}, \mathrm{dd}, J=6.4 \mathrm{~Hz}, 3.2 \mathrm{~Hz}, \mathrm{C} 6, \mathrm{C} 7), 7.16(2 \mathrm{H}, \mathrm{s}, \mathrm{C} 1, \mathrm{C} 4), 4.13(4 \mathrm{H}, \mathrm{t}, J=6.6 \mathrm{~Hz} \mathrm{OCH})^{2}, 1.91(4 \mathrm{H}, \mathrm{p}$, $\left.J=7.2 \mathrm{HzOCH}_{2} \mathrm{CH}_{2}\right) 1.52\left(4 \mathrm{H}, \mathrm{m}, \mathrm{OCH}_{2} \mathrm{CH}_{2} \mathrm{CH}_{2}\right), 1.44-1.27\left(24 \mathrm{H}, \mathrm{m}, \mathrm{OCH}_{2} \mathrm{CH}_{2} \mathrm{CH}_{2}\left(\mathrm{CH}_{2}\right)_{6} \mathrm{CH}_{3}\right), 0.88\left(6 \mathrm{H}, \mathrm{t}, J=7.0 \mathrm{~Hz}, \mathrm{CH}_{3}\right) .{ }^{13} \mathrm{CNMR}\left(100 \mathrm{MHz}, \mathrm{CDCl}_{3}\right)$ : $\delta 150.0$ (C2, C3), 130.7 (C8a, C10a), 128.7 (C8, C5), 127.6 (C6, C7), 124.4 (C9, C10), 123.7(C1, C14), 105.9 (OCH (OC) $_{2} 68.7\left(\mathrm{OCH}_{2} \mathrm{CH}_{2}\right), 32.0,29.7$, 29.6, 29.5, 29.4, 29.1, 26.2, $22.7\left(\mathrm{CH}_{2} \mathrm{CH}_{3}\right), 14.2\left(\mathrm{CH}_{3}\right)$. FTIR (neat, ATR diamond): $v_{\max }\left(\mathrm{cm}^{-1}\right) 3046\left(\mathrm{~s}, v \mathrm{CH}\right.$ aromatic), $2916\left(v_{\text {as }} \mathrm{CH} \mathrm{H}_{2}\right.$ alkyl), 2850

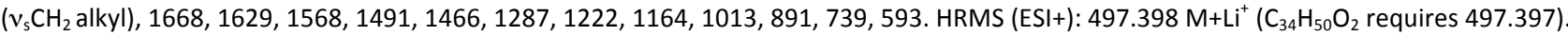

\section{NMR experiments.}

Materials. BHPB10 was synthesized according to a published procedure. ${ }^{1}$ HSA was purchased from Aldrich and used as is. DDOA was synthesized by a modified procedure from the literature ${ }^{2}$ (see supp. info). 
Variable temperature NMR. The NMR spectra were measured at different temperatures on a Bruker Avance III spectrometer operating at 600 $\mathrm{MHz}$. The temperature of the probe was calibrated by two methods : with a thermocouple inserted in a sample; from the shifts of methanol at different temperatures. ${ }^{3}$ both methods yielded the same temperatures within $\pm 0.4^{\circ} \mathrm{C}$.

In a typical experiment, the required amount of the gelator was weighed on a precision balance (accuracy $\pm 20 \mu \mathrm{g}$ ) in a NMR tube. A standard bis(trimethylsilyl)acetylene (BTMSA) was introduced by adding a weighed amount ( $20 \mathrm{mg}$ ) of a solution in the deuterated solvent ( 2 wt. \% solution). The rest of the deuterated solvent (about $0.5 \mathrm{~mL}$ ) was weighed in the tube to match the desired wt. concentration.

The temperature was incremented by steps of 1 or $2{ }^{\circ} \mathrm{C}$. After each heating steps, the sample temperature was allowed to stabilize and equal the targeted temperature within $\pm 0.1{ }^{\circ} \mathrm{C}$, at least during $40 \mathrm{~s}$ and the sample was let equilibrate at this temperature for additional 3 to 4 min. The FID were measured only after this delay. The overall heating rate was about $0.25^{\circ} \mathrm{C} / \mathrm{min}$.

The recycling times and pulse angles were tuned to reach a good compromise between experiment duration and minimizing errors of integration. For instance, longitudinal relaxation times $T_{1}$ of the proton of HSA at $3.6 \mathrm{ppm}$ (Fig. 2) $T_{1}$ varies from 6.3 to $1.5 \mathrm{~s}$ when the temperature increases, and for the protons of the standard $T_{1}$ varies from 3.3 to $6.1 \mathrm{~s}$. The recycling time has been set to $18 \mathrm{~s}$ and the pulse angle at $30^{\circ}$. The resulting error has been taken into account to estimate the overall errors (see below).

The measured intensities $I_{\mathrm{m}}$ were normalized to the integrals of the peaks of the standard $I_{\mathrm{st}}$ (Fig. S1). The normalized intensities are noted $I$ (I $=I_{\mathrm{m}} / I_{\mathrm{st}}$ ). It was ensured that the ratio between this signal and that of the residual protonated solvent was constant. Therefore, when the signals of the solvent did not overlap with that of the gelators, it was possible to normalize the spectra by their intensities. The intensities of several peaks of the gelator were measured either by direct integration, either by fitting the peaks with lorentzian peaks. When the gel was melted, the intensities of the peaks reached a plateau. The values of the intensities of the plateau were averaged and the average value was taken as $I_{\max }$. The uncertainty on the average of the plateau estimated as the peak-to-peak deviation (about $2 \%$ ).

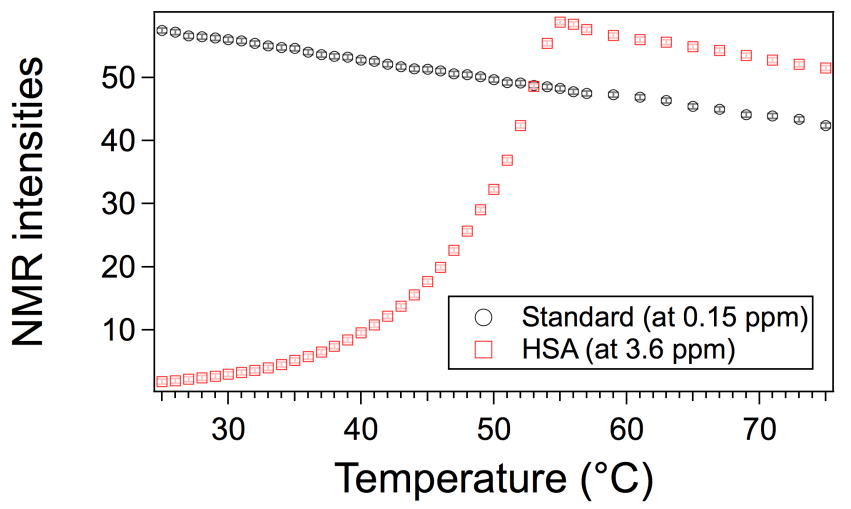

Figure S1. NMR integrals of the peak at $3.6 \mathrm{ppm}$ of HSA and the peak of the standard (BTMSA).

The intensities I of the peaks of the gelators were converted to the weight concentrations with eq. 1.

$$
c=c_{t} \frac{I}{I_{\max }} /\left[1+c_{t}\left(\frac{I}{I_{\max }}-1\right)\right]
$$

where $c_{\mathrm{t}}$ is the total wt. concentration of the gelator, $I_{\max }$ is the averaged intensity of the peak in the plateau. $I_{\text {max }}$ has been measured after averaging the intensities in the plateau. For low concentrations, c can be approximated by eq. 2 with an uncertainty less than $0.5 \%$.

$$
c=c_{t} \frac{I}{I_{\max }}
$$

Equal weight fractions in deuterated and protonated solvents do not represent the same molar concentration. Therefore, the plots mixing results in deuterated solvent with results in protonated solvent were represented with molar fractions in abscissa. The molar fractions $X$ were calculated form the NMR intensity according equation (3)

$$
X=X_{t} \frac{I}{I_{\max }} /\left[1+X_{t}\left(\frac{I}{I_{\max }}-1\right)\right]
$$

where $X_{\mathrm{t}}$ is the total molar fraction. For low concentration $\mathrm{X}$ can be approximated by an equation similar to eq. 2 .

The calculation of the concentrations gave similar results with intensities measured by integrations or by fitting, within less than $1 \%$ error for higher temperatures and less than $5 \%$ for the lower temperatures. The uncertainty of $c$ or $X$ was appraised by taking into account the signal/noise ratio (SNR), the incomplete integration range $(\sim 2 \%),{ }^{4}$ the uncertainty on mass $(\sim 1 \%)$, the error due to incomplete relaxation. The error due to SNR is about constant with temperature, therefore the uncertainty on the NMR intensities decreases from $1 \%$ at the plateau to large values at low $T$ and $c$. The lower concentrations, with a high uncertainty (>50\%) have been discarded (although in line with higher $c$ values).

3. DSC. The thermograms were recorded with a SETARAM III microcalorimeter. The measuring cell was filled with a gelator/solvent mixture (between 100 and $200 \mathrm{mg}$ ). The reference cell was filled with a mass of pure solvent equal to that of the first cell within $0.1 \mathrm{mg}$. The gel was formed during a first cycle of heating at $1{ }^{\circ} \mathrm{C} / \mathrm{min}$ and cooling at $0.3^{\circ} \mathrm{C} / \mathrm{min}$. The thermograms were measured during a second cycle at heating and cooling rates close to the overall rate of the NMR experiments $\left(0.25^{\circ} \mathrm{C} / \mathrm{min}\right)$.

4. Rheology. The real and imaginary parts of the shear modulus were measured as a function of temperature as described previously. ${ }^{5}$ The temperature of gel-to-sol transition is defined by the temperature for which the elastic modulus $G^{\prime}$ and loss modulus 
$G^{\prime \prime}$ cross over. Each transition temperature was measured for decreasing stress values and the temperature was deduced from a null stress extrapolation. This caution avoids measuring a decrease of $G^{\prime}$ because it flows under a high stress.

\section{Solubility assays.}

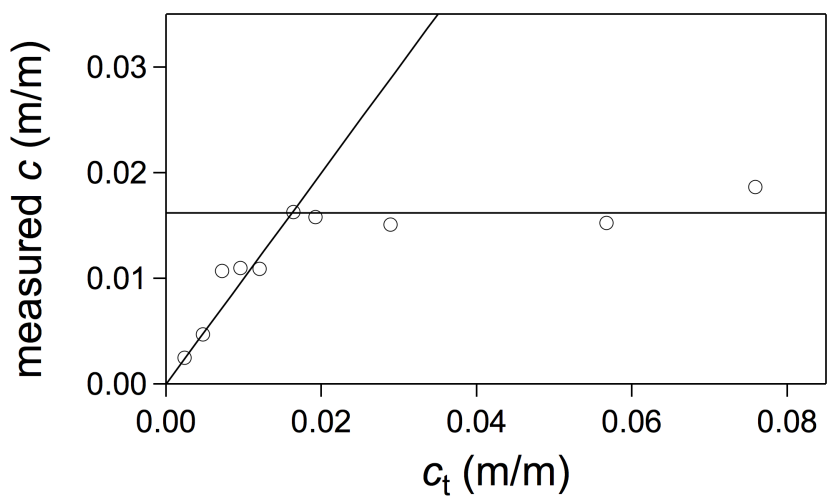

Figure S2. Saturation experiment at $48^{\circ} \mathrm{C}$ with Hirst et al. method ${ }^{2}$ Measured NMR intensities against total concentration $c_{\mathrm{t}}$.

\section{Bibliography}

(1) Pozzo, J.-L.; Clavier, G. M.; Colomes, M.; Bouas-Laurent, H. Different Synthetic Routes towards Efficient Organogelators: 2,3Substituted Anthracenes. Tetrahedron 1997, 53, 6377-6390.

(2) Hirst, A. R.; Coates, I. A.; Boucheteau, T. R.; Miravet, J. F.; Escuder, B.; Castelletto, V.; Hamley, I. W.; Smith, D. K. Low-Molecular-Weight Gelators: Elucidating the Principles of Gelation Based on Gelator Solubility and a Cooperative Self-Assembly Model. J. Am. Chem. Soc. 2008, 130, 9113-9121. 